\title{
A Biomechanical Comparison of Three Sternotomy Closure Techniques
}

\author{
COL David J. Cohen, MD, USA, and Lanny V. Griffin, PhD
}

Background. A biomechanical study of three sternotomy closure techniques (figure-of-eight stainless-steel wires, Pectofix Dynamic Sternal Fixation [DSF] stainlesssteel plates, and figure-of-eight stainless-steel cables) was conducted to compare strength and stiffness variables in three clinically relevant loading modes (anteriorposterior shear, longitudinal shear, and lateral distraction).

Methods. All tests were conducted on polyurethane foam sternal models that simulate the properties of cancellous bone. Each model was divided longitudinally and reconstructed using one of the sternotomy closure repair techniques. Tests were performed using a materials testing system that applies a continuously increasing amount of force in one direction to the model until it catastrophically breaks. A total of six trials of each fixation type in each of three test groups were prepared and tested, for a total of 54 tests. Strength and stiffness variables as well as a post-yield analysis of failure were evaluated.

Results. Sternums repaired using the DSF plate system are a more rigid construct than sternums repaired using

$\mathrm{T}$ he stainless-steel cerclage wire used as either interrupted simple sutures or as figure-of-eight sutures is the current standard method of median sternotomy closure in cardiothoracic operations [1, 2]. Although the wire method is widely used, complications related to sternum nonunion or malunion can lead to hardware failure, incisional pain caused by sternal motion, reoperation, infection, sepsis, and, occasionally, death [3-7].

In general, good results can be obtained if the closure method provides good rigidity and strength. Rigidity of the reduction is very desirable as it leads to less motion under load and may promote better healing rates, and higher strength will prevent failure of the construct during the healing process. Clinically, failure of the wire system usually involves the wire cutting into the bone under loads [8]. This cutting of wire into the bone produces a separation of the sternum, which can result in a nonunion and other complications. It was hypothesized the stainless-steel wires or cables in the distraction and transverse shear modes and they are not significantly different from sternums repaired with wires or cables in the longitudinal shear mode. The DSF plate system offers a $25 \%$ improvement in resistance to failure (yield) compared to wires when a transverse shear force is applied to the model. The cable system had a higher resistance to failure than the wires in all modes although the differences were not statistically significant. Additionally, the DSF plate system provides substantial reduction of the implant's cutting into the sternal model under loading as evidenced by the post-yield displacement when compared with either cables or wires for the distraction and longitudinal shear modes. For the transverse shear mode, the cables or wires would completely fail at the load for which cutting begins for the DSF.

Conclusions. Both the DSF plate system and the stainless-steel cable system offer important advantages over figure-of-eight wire for sternal closure.

that either a sternotomy closure system that uses crimped stainless-steel cables or a system that uses small stainless-steel plates to distribute local stresses of the wires on the sternum will result in higher strength and better rigidity, which will facilitate bone healing and reduce postoperative complications.

Because of the tremendous variability in bone density, sternal size, and sternal thickness between cadaver specimens and because of significant differences in shape and size between the human sternum and that of common four-legged domestic animals such as the dog, sheep, pig, and cow, a model sternum was selected in which to test sternal closure techniques. The use of synthesized polyurethane foam models for development and testing of orthopedic appliances is a common technique. Different weights of compressed foam have been characterized and can be constructed to simulate cancellous or cortical bone [9]. Although not exactly the same as a biologic specimen, these models allow reproducibility in testing and permit reasonable expectations as to how a mechanical appliance will perform in bone.

Materials testing is destructive in nature. The tests can be repetitive so as to measure fatigue or they can be monotonic, which means that the device or construct is 


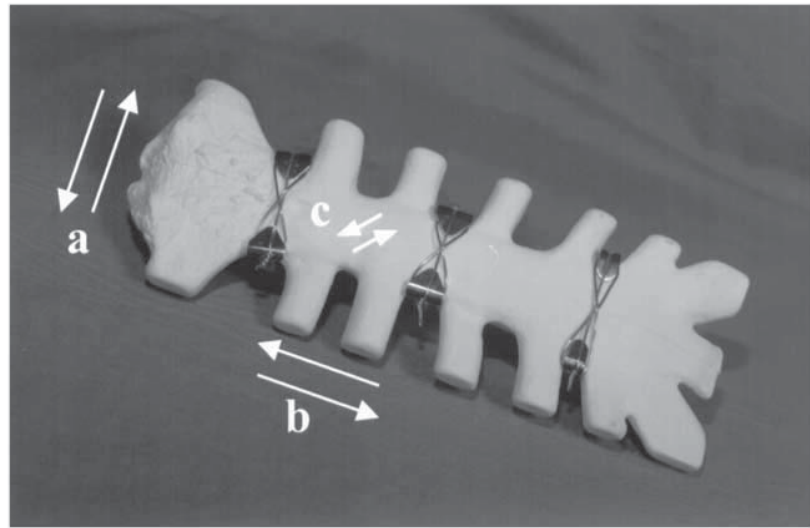

Fig 1. Directions of load application on sternal models. (a = lateral distraction; $\mathrm{b}=$ longitudinal shear; $\mathrm{c}=$ transverse shear.)

stressed in one direction with a constantly increasing force until it breaks or fails.

In the current study, models were sawed in half, repaired using one of three techniques, and then they were stressed in one of three directions until they broke using a hydraulic testing machine. The three directions in which stress was applied were lateral distraction, longitudinal shear, and transverse shear (Fig 1).

The engineering test system pulls the construct apart until it breaks, while graphing the force applied versus separation (displacement) This generates a loaddisplacement curve from which a number of variables can be interpreted (Fig 2).

Four biomechanical variables were considered in this study: yield load, construct rigidity (stiffness), ultimate load, and displacement at ultimate load, as well as post-yield behavior. The stiffness is measured as the slope of the initial linear portion of the loaddisplacement curve (Fig 2). Physically, a higher stiffness system will produce less motion when compared with a system with lower stiffness. A completely rigid (or infinitely stiff) fixation would produce no motion under loading. In general, higher stiffness is desirable as it leads to less movement when a force is applied. As a rule, the stiffness measures recoverable deformation under loading, meaning that if the load is removed, the displacement will return to its preloaded value and the object or construct is not permanently deformed.

The yield point is that point on the curve where the force-displacement curve becomes nonlinear. This is important because yielding is associated with the initiation of some localized failure. This is a nonreversible process, meaning that displacement will not return to zero, even if the load is completely removed. For this variable, higher yield loads are desirable, implying that greater forces are necessary to deform the object.

The maximum load measures the ultimate strength of the construct. These are engineering terms that denote the force necessary to catastrophically destroy the object. For this variable, higher maximum load is preferable. The displacement at ultimate load is a measure of how much displacement has occurred at the point where the construct catastrophically fails. Less displacement at the maximum load is preferable because it implies that most of the deformation is reversible if the force is removed before failure of the construct.

The purposes of this study were to compare the yield load, construct stiffness, ultimate load, displacement at ultimate load, and post-yield behavior of three sternotomy closure methods when stressed in each of three directions: lateral distraction, rostral-caudal (longitudinal) shear distraction, and anterior-posterior (transverse) shear (Fig 1).

\section{Material and Methods}

Tests were conducted using custom sternal models manufactured of $20 \mathrm{lb} / \mathrm{ft}^{3}$ rigid polyurethane foam designed to simulate the properties of cancellous bone (Pacific Research Labs Inc, Vashon Island, WA) [9]. The sternal model included the manubrium and surrounding six ribs with approximately $2.5 \mathrm{~cm}$ of rib extending from the sternum. Each sternal model was divided longitudinally using a band saw. The sternotomy was closed by a cardiothoracic surgeon using three peristernal figure-ofeight No. 5 stainless-steel wires (Ethicon, Inc, Somerville, $\mathrm{NJ}$ ), three figure-of-eight stainless-steel cables (Pioneer Surgical Technology, Marquette MI), or three pairs of stainless-steel plates (DSF Dynamic Sternal Fixation System, Pectofix Inc, South Plainfield, NJ) (Figs 3,4).

The ribs were embedded into specially designed cups using polymethylmethacrylate (Palacos R, Smith \& Nephew, Memphis, TN) and secured transversely by three cotter pins. The models then were attached to custom fixtures designed to produce displacement in one of three modes: longitudinal (rostral-caudal) shear of the

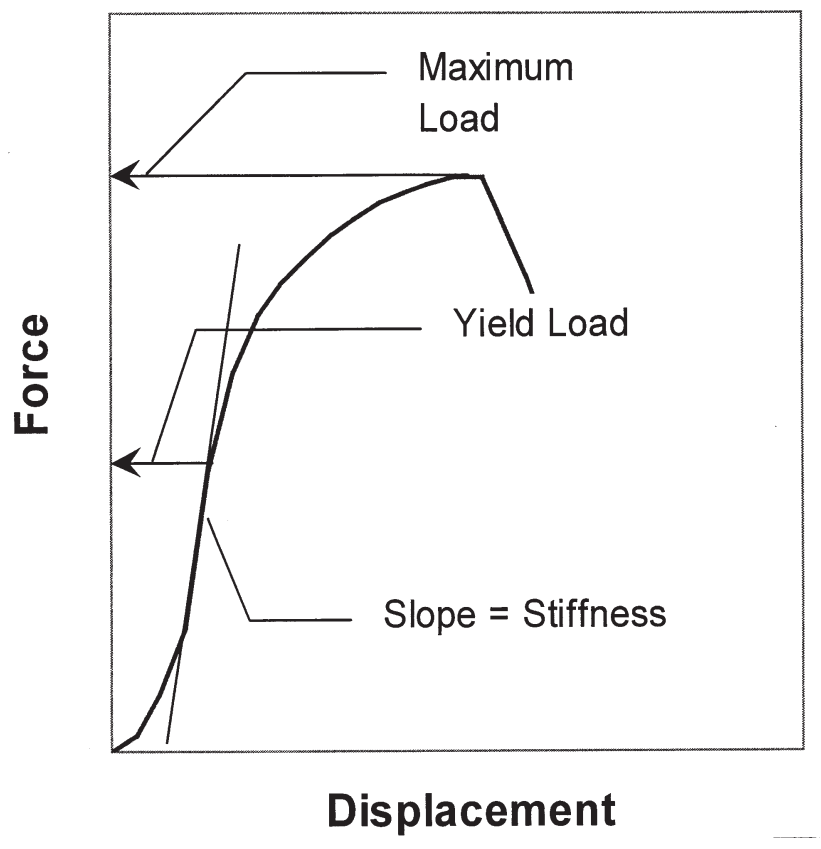

Fig 2. Load-displacement curve and definitions of terms. Stiffness is the slope of the linear portion of the curve. The yield load is the force applied that causes the curve to become nonlinear. Above this point of the curve, displacement is at least partially irreversible after removing the force. Maximum load is the force required to cause catastrophic failure of the system. 


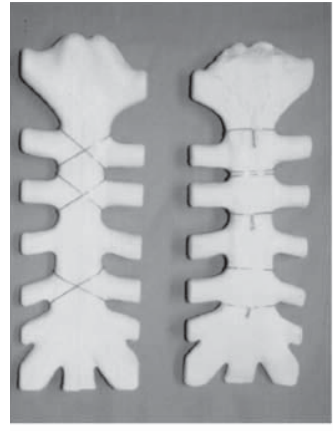

a

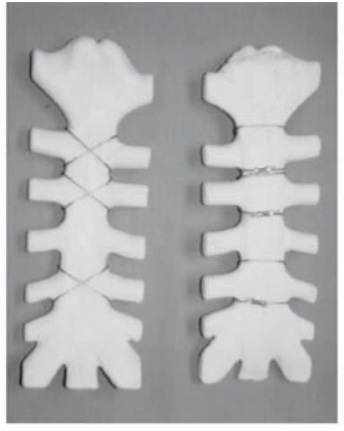

b

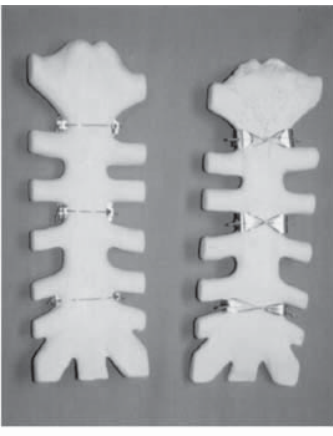

c
Fig 3. Photographs of models closed with each test system. $(\mathrm{a}=$ figure-of-eight stainless-steel wire; $\mathrm{b}=$ figure-of-eight stainlesssteel cable; $\mathrm{c}=$ dynamic sternal fixation system sternal plates.) sternum, transverse (anterior-posterior) shear of the sternum, or distraction of the sternum under loading (Fig 5). The rib/fixture assembly was then placed in a servohydraulic materials testing system (model 8521s, Instron Corp, Canton, MA).

Within each of the three experimental groups, six tests of each fixation method and in each direction previously listed were conducted with each method being selected at random by using a cyclic permutation scheme. Each of the 54 tests was conducted under displacement control mode to pull the specimen apart at a constant rate of 10 $\mathrm{mm} / \mathrm{min}$ until failure, which was defined as the point at which fracture of the sternum, ribs, or construct occurred. The electronic controls of the materials testing system digitally acquired load and displacement data. After each test, the specimen was visually examined to determine the mode of failure and photographed. For each loading mode, eg, longitudinal shear, a one-factor analysis of variance model was used to determine whether differences in the mean values of the continuous response variables obtained from the biomechanical testing, such as yield strength, were significant. The treatment was the biomechanical construct, ie, figure-of-eight wires, DSF system, or cables. Post hoc multiple comparisons were performed using Fisher's exact test. Differences were considered significant if $p$ was less than 0.05 .

\section{Results}

The mean values of biomechanical variables are listed in Table 1 . The individual variables are directly compared in graphical form. Figure 6 summarizes the stiffness obtained for all the tests. In the transverse shear direction, the plates are stiffer than the cable or figure-of-eight wire constructs $(p=0.003)$. There were no statistical differences in the other directions. Figure 7 summarizes the yield strengths for the tests. For this variable, a higher value is very desirable. For all of the modes that were evaluated, both the plates and cables were stronger than the wires. Only the differences for the transverse shear mode are statistically significant $(p=0.021)$.

Figure 8 summarizes the maximum loads obtained for all the tests. For this variable, larger is better although the importance of this load must be assessed by considering all other factors, particularly yield loads, post-yield displacement, and stiffness. For the lateral distraction and longitudinal shear modes, all the constructs are essentially equal in strength. For the transverse shear mode, the DSF plates are significantly stronger than either the wires or cables.

Figure 9 compares the post-yield displacement (ie, how much displacement occurred between the onset of initial yield or failure and final failure) of the various constructs. A low number for this measurement is more desirable. For the distraction mode and longitudinal shear mode, the wires had a greater post-yield displacement resulting from the wire cutting into the sternal model. For the transverse shear mode, the plates had significantly greater post-yield displacement than either the wires or cables.

\section{Comment}

Poor sternal healing leading to sternal separation and dehiscence is a significant complication after median sternotomy which occurs in $0.5 \%$ to $2.5 \%$ of cases $[10,11]$. Sternal dehiscence leads to discomfort, mediastinitis, osteomyelitis, and chronic sternal instability, and it is associated with a $10 \%$ to $40 \%$ mortality rate $[12,13]$. Bitkover and coworkers [14], in a prospective computed tomography scan study of sternal healing after median sternotomy, found that there was no sternal healing 3 months after operation and complete healing in only half of the patients by 6 months after operation. The method of sternal repair thus seems to be of great importance to long-term sternal stability.

McGregor and associates [8] studied sternal closure using interrupted No. 5 stainless-steel wires around the sternum in a human cadaver model. They demonstrated that at physiologic loads, sternal dehiscence occurs with greatest separation in the lateral displacement direction.
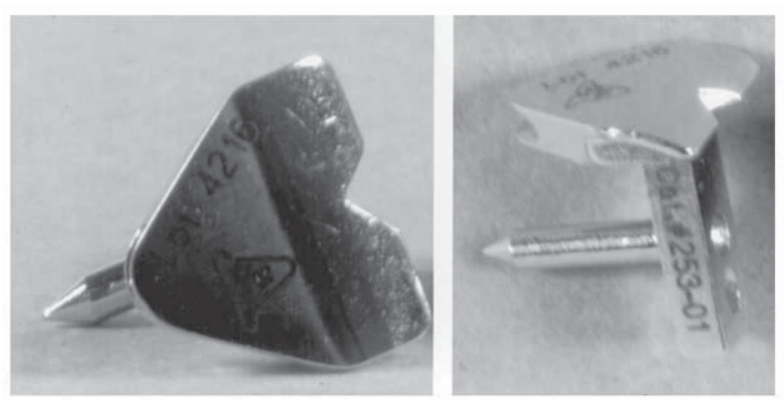

Fig 4. Closeup views of Dynamic Sternal Fixation system sternal plates. 
Fig 5. Custom fixture allowing mounting of specimens into test stand to apply lateral distraction (a) longitudinal shear (b), or transverse shear (c).

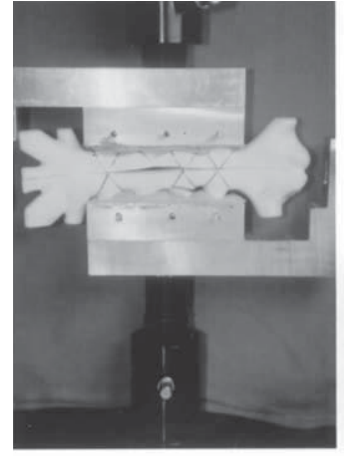

a
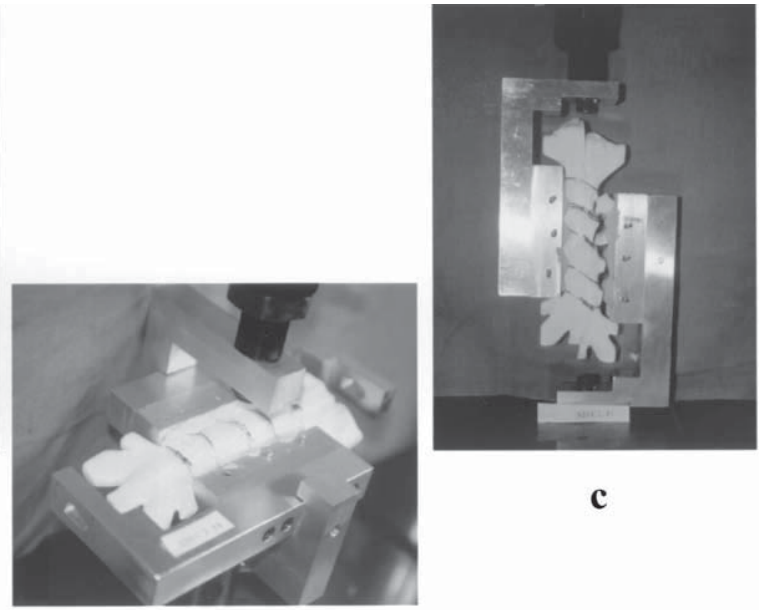

c

b

In a biomechanical study using human cadaver sternum, Ozaki and colleagues [15] used several different configurations of titanium plates and screws to close the sternum and compared them with wire closure. The geometry of each type of plate and screws were different and led to vast differences in effectiveness of closure and rigidity of the complex. Hendrickson and coworkers [16] have developed a screw and compression plate system that they have used clinically.

In the current study three techniques of sternal closure were studied. The standard figure-of-eight wire closure was compared with closure with a figure-of-eight cable system and a unique sternal plating system. Cables offer significantly greater tensile strength than a single wire and avoid the kinking in the body of the wire and at the site of twisting that leads to stress concentrations and areas of weakness. The cable system uses a torque wrench device that tightens it to a uniform load avoiding over-tightening or under-tightening, and it uses a crimp to secure the cable that avoids twisting. The larger cross-sectional diameter of the cable may decrease the tendency for the cable to cut into bone.

Several forces act on the sternum. Normal breathing and coughing load the sternum through a combination of lateral displacement and transverse shear whereas lon- gitudinal shear is applied to the sternum during skeletal movement, particularly when patients are using their arms to get in and out of bed. The DSF system uses stainless-steel Pectofix plates (Fig 4). These plates protect the wire from cutting into the bone. The triangular design of the plate with its anterior figure-of-eight wire configuration stabilizes the outer table of the sternum. Distractive forces encountered during coughing or breathing are neutralized by the anterior repair resulting in compression of the inner table of the sternum. This is the principle of tension band repair, which is used in a number of orthopedic procedures [17]. Using other systems, the sternal closure is subjected to distraction during chest expansion. The plates also decrease the stress on the sternum by distributing the forces over a larger area.

We predicted that the plates would provide a more stable and stronger construct than either the wires or cables. To better appreciate the relative performance of the various systems, we will discuss each variable separately.

\section{Rigidity}

From the data shown in Table 1 and Figure 6, the DSF plates provide a more rigid (stiff) construct than the wires

Table 1. Biomechanical Variable Averages for Sternotomy Closure Evaluations

\begin{tabular}{|c|c|c|c|c|c|c|}
\hline Loading Mode & Fixation & $\begin{array}{l}\text { Stiffness } \\
(\mathrm{KN} / \mathrm{mm})\end{array}$ & $\begin{array}{l}\text { Yield Load } \\
\quad(\mathrm{KN})\end{array}$ & $\begin{array}{c}\text { Displ. at } \\
\text { Yield (mm) }\end{array}$ & $\begin{array}{l}\text { Maximum } \\
\text { Load }(\mathrm{KN})\end{array}$ & $\begin{array}{l}\text { Post-yield } \\
\text { Displ. (mm) }\end{array}$ \\
\hline \multirow[t]{3}{*}{ Distraction } & Plate & 1.53 & 0.71 & 1.30 & 1.58 & 1.10 \\
\hline & Wire & 1.30 & 0.63 & 1.37 & 1.55 & $3.65^{*}$ \\
\hline & Cable & 1.35 & 1.223 & 1.41 & $1.89^{\mathrm{b}}$ & 1.81 \\
\hline \multirow[t]{3}{*}{ Longitudinal shear } & Plate & $0.118^{*}$ & 1.35 & 11.49 & 1.49 & $3.55^{*}$ \\
\hline & Wire & 0.09 & 1.09 & 12.33 & 1.59 & 9.41 \\
\hline & Cable & 0.103 & 1.30 & 12.30 & 1.57 & 5.04 \\
\hline \multirow[t]{3}{*}{ Transverse shear } & Plate $^{\mathrm{a}}$ & $0.12^{*}$ & $0.83^{*}$ & 8.73 & $1.21^{*}$ & $5.35^{* \mathrm{c}}$ \\
\hline & Wire & 0.07 & 0.62 & 8.94 & 0.71 & 1.88 \\
\hline & Cable & 0.09 & 0.69 & 9.54 & 0.75 & 1.14 \\
\hline
\end{tabular}

Data denoted by an asterisk are significant $(p<0.05)$. KN is kilonewtons of force.

${ }^{a}$ Performed best by all measures. $\quad{ }^{\mathrm{b}}$ Nearly significant $(p=0.067) . \quad{ }^{\mathrm{c}}$ Due to cutting of sternum under loading (an undesirable failure). 


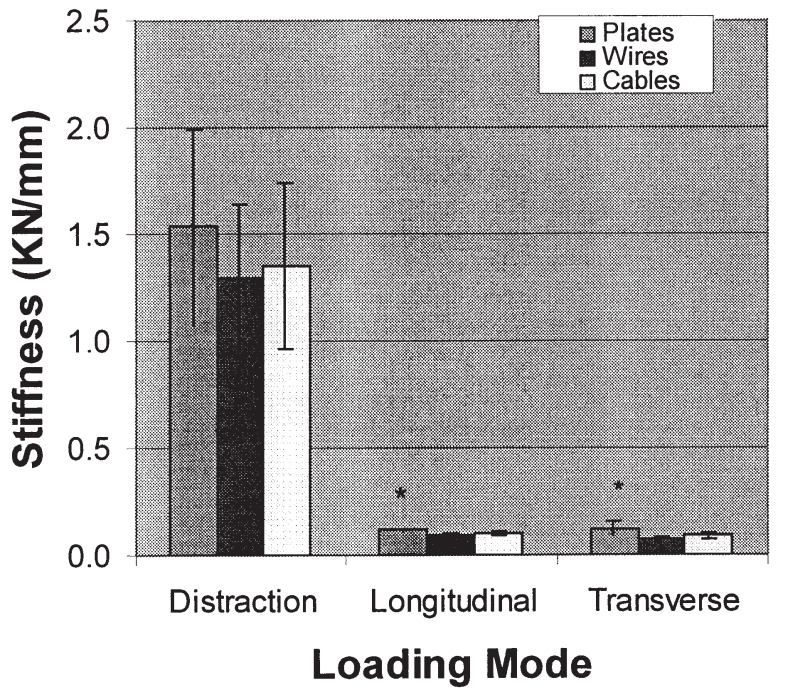

Fig 6. Rigidity (stiffness) of the various fixation methods. Data denoted by an asterisk are significant $(\mathrm{p}<0.05)$. Columns denote mean values. Error bars denote \pm 1 standard deviation. Stiffness is measured in kilonewtons of force per millimeter displacement.

and cables for the transverse shear mode. Higher rigidity is very important because it means less motion when the sternum is stressed, which should create a favorable condition for healing of the sternum.

\section{Yield Strength}

From the data in Figure 7, it is clear that the DSF plates and cables offer improved resistance to yield when compared with the wires for all the modes tested. This is important in that it suggests that the DSF plates and cables are able to sustain higher loads without irreversible damage to the sternum and closure hardware. The yield load for wires is the load at which the wire begins to cut into the sternal model. This is an irreversible process and can lead to separation at the sternotomy closure site

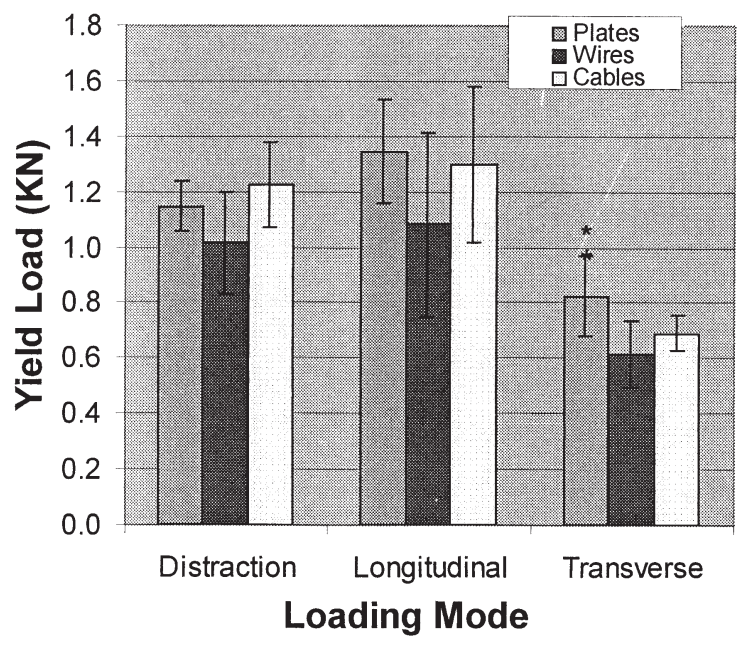

Fig 7. Yield loads for the tests conducted. Data denoted by an asterisk are significant $(\mathrm{p}<0.05)$. Columns denote mean force in kilonewtons at which irreversible distortion of the specimen construct first occurs. Error bars denote \pm 1 standard deviation.

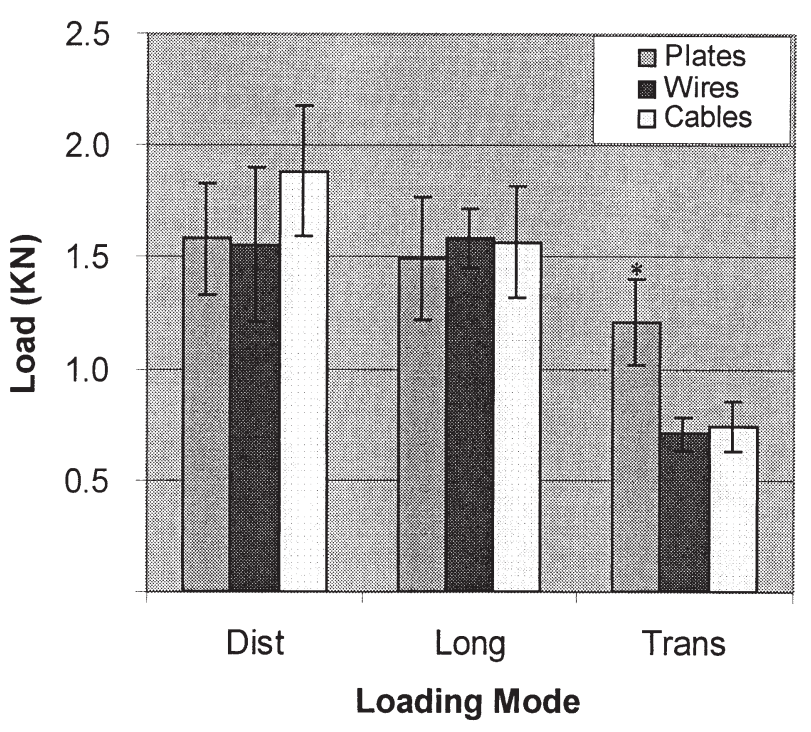

Fig 8. Maximum loads for the tests conducted. Data denoted by an asterisk are significant $(\mathrm{p}<0.05)$. Columns denote load in kilonewtons at which catastrophic failure of the construct occurred. Error bars signify \pm 1 standard deviation. (Dist $=$ lateral distraction; Long = longitudinal shear; Trans $=$ transverse shear.)

even if the load is removed. Clinically, a higher yield strength may reduce complications related to sternal dehiscence. For the transverse shear mode, the DSF plate system was stronger than either the cables or the wires, and this difference was statistically significant even with the small sample size. Yield strength did not differ significantly among closure mode for the other directions of force application.

\section{Maximum Strength and Post-Yield Displacement}

The data in Figures 8 and 9 are necessary to determine the relative merits of the devices evaluated. In the dis-

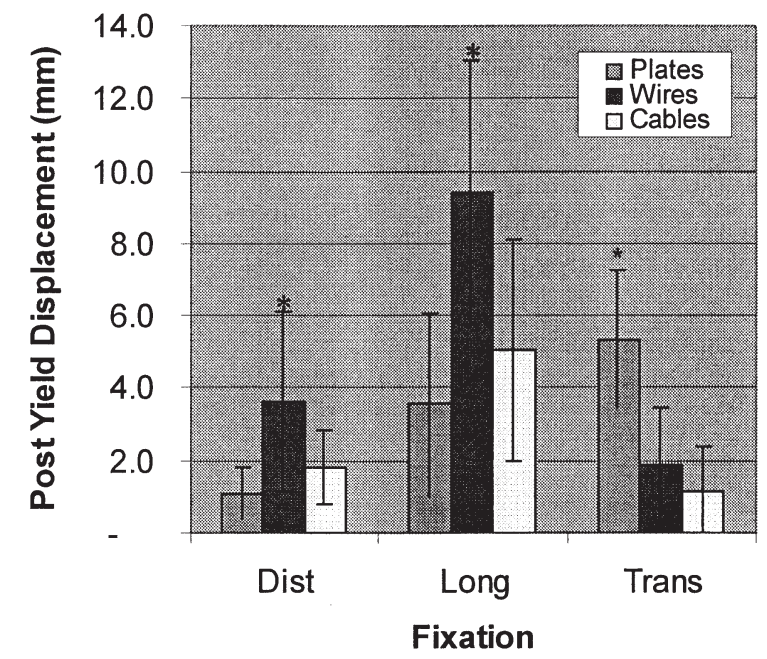

Fig 9. Post-yield displacement for all the tests. Data denoted by an asterisk are significant $(\mathrm{p}<0.05)$. Columns denote displacement in millimeters occurring between the application of sufficient force to initiate irreversible distortion of the construct and the application of enough force to cause catastrophic failure. Error bars signify \pm 1 standard deviation. (Dist = lateral distraction; Long = longitudinal shear; Trans = transverse shear.) 
traction mode and in the longitudinal shear mode, the wires have the largest post-yield displacement, indicating that the wires are cutting into the sternal model. Such a failure is not desirable as it can lead to malunion or nonunion of the sternotomy or other postoperative complications. It is important to minimize this factor.

The relatively large value of the post-yield displacement of the DSF plates in transverse shear was associated with cutting of the sternal model on its posterior aspect. However, it is very important to note that the transverse shear yield load of the DSF plate system was more than $9.5 \%$ greater than the load that would cause catastrophic failure for the cables or the wires under transverse shear loading, and the maximum transverse shear load supported by the DSF plate system was significantly greater than that for the cable or wire systems $(p<0.001)$. Therefore, the DSF plate system performs substantially better than the wires or cables for this important loading mode.

\section{Conclusions}

1. The DSF plate system is a more rigid construct than figure-of-eight stainless-steel wires or stainlesssteel cables when transverse shear force is applied to the sternal model.

2. The DSF plates offer a $25 \%$ improvement in resistance to failure (yield) over figure-of-eight wires when a transverse shear force is applied. The cable system had higher resistance to failure than the DSF plates in the lateral distraction mode, and the cable system had higher resistance to failure than the figure-of-eight wires in all modes. None of these differences were statistically significant, however.

3. The DSF plates provide substantial and significant reduction of cutting into the sternum under loading as evidenced by the post-yield displacement when compared with either cables or wires for the distraction and longitudinal shear modes. For the transverse shear mode, the cables or wires would completely fail at the load for which cutting into the sternal model begins with the DSF plates.

4. The use of synthetic sternal models, which simulate cancellous bone, allows testing of sternal stability in which the only variable is method of closure. In a living patient many other factors have been implicated in sternal wound complications including obesity, diabetes, chronic obstructive lung disease, age, smoking history, bilateral internal thoracic artery grafting, reoperation, and postoperative inotropic support [18-22]. These patient factors may have different effects on each closure system.

5. Both the DSF plate system and the stainless-steel cable system offer important advantages over figure-of-eight wire closure.

\section{References}

1. Julian OC, Lopez-Belio M, Dye WS, Javid H, Grove WJ. Appraisal of progress in surgical therapy: the median sternal incision in intracardiac surgery with extracorporeal circulation; a general evaluation of its use in heart surgery. Surgery 1957;42:753-61.

2. Goodman G, Palatianos GM, Bolooki H. Technique of closure of mediansternotomy with trans-sternal figure-of-eight wires. J Cardiovasc Surg 1986;27:512-3.

3. Sanfelippo PM, Danielson GK. Complications associated with median sternotomy. J Thorac Cardiovasc Surg 1972;63: 419-23.

4. Serry C, Bleck PC, Javid H, Hunter JA, Golden MD, DeLaria GA. Sternal wound complications, management and results. J Thorac Cardiovasc Surg 1980;80:861-7.

5. Bitkover CY, Gardlund B. Mediastinitis after cardiovascular operations: a case-control study of risk factors. Ann Thorac Surg 1998;65:36-40.

6. Sarr MG, Gott VL, Townsend TR. Mediastinal infection after cardiac surgery [Review]. Ann Thorac Surg 1984;38:415-23.

7. Stoney WS, Alford WC Jr, Burrus GR, Frist RA, Thomas CS. Median sternotomy dehiscence. Ann Thorac Surg 1978;26: 421-6.

8. McGregor WE, Trumble DR, Magovern JA. Mechanical analysis of midline sternotomy wound closure. J Thorac Cardiovasc Surg 1999;117:1144-50.

9. Szivek JA, Thomas M, Benjamin JB. Characterization of a synthetic foam as a model for human cancellous bone. J Appl Biomater 1993;4:269-72.

10. Del Campo C, Heimbecker RO. Repair of refractory sternal dehiscence: a new technique. J Thorac Cardiovasc Surg 1982; 83:937-8.

11. Stahle E, Tammelin A, Bergstrom R, Hambreus A, Nystrom SO, Hansson HE. Sternal wound complications-incidence, microbiology and risk factors. Eur J Cardiothorac Surg 1997; 11:1146-53.

12. Tavilla G, van Son JAM, Verhagen AF, Lacquet LK. Modified Robiscek technique for complicated sternal closure. Ann Thorac Surg 1991;52:1179-80.

13. Goldman G, Nestel R, Snir E, Vidne B. Effective technique of sternum closure in high risk patients. Arch Surg 1988;123: 386-7.

14. Bitkover CY, Cederlund K, Aberg B, Vaage J. Computed tomography of the sternum and mediastinum after median sternotomy. Ann Thorac Surg 1999;68:858-63.

15. Ozaki W, Buchman S, Iannettoni MD, Frankenburg EP. Biomechanical study of sternal closure using rigid fixation techniques in human cadavers. Ann Thorac Surg 1998;65: 1660-5.

16. Hendrickson SC, Koger KE, Morea CJ, Aponte RL, Smith PK, Levin LS. Sternal plating for the treatment of sternal nonunion. Ann Thorac Surg 1996;62:512-8.

17. Muller ME, Allgower M, Schneider R, Willenegger $H$, eds. Manual of internal fixation: techniques recommended by the AO-group, 2nd ed, expanded and revised. Berlin: SpringerVerlag, 1979:42-3.

18. Zacharias A, Habib RH. Factors predisposing to median sternotomy complications: deep vs superficial infection. Chest 1996;110:1173-8.

19. Bryan AJ, Lamarra M, Angelini GD, West RR, Breckenridge IM. Median sternotomy wound dehiscence: a retrospective case control study of risk factors and outcome. J Royal Coll Surg Edinb 1992;37:305-8.

20. Demmy TL, Park SB, Liebler GA, et al. Recent experience with major sternal wound complications. Ann Thorac Surg 1990;49:458-62.

21. Hazelrigg SR, Wellons, HA Jr, Schneider JA, Kolm P. Wound complications after median sternotomy: relation to internal mammary grafting. J Thorac Cardiovasc Surg 1989;98:1096-9.

22. Parisian Mediastinitis Study Group. Risk factors for deep sternal wound infection after sternotomy: a prospective multicenter study. J Thorac Cardiovasc Surg 1996;111:1200-7. 